\title{
Raylı Sistem İstasyon Yeri Belirleme Problemi İçin Küme Kapsama ve Alternatif Servis Seviyeli P-Medyan Modelleriyle Çözüm Arayışı: Gebze-Darıca Metro Hattı Uygulaması
}

\section{Seeking Solution with Set Covering and Alternative Service Level P-Median Models for Rail System Station Locating Problem: Gebze-Darıca Metro Line Application}

\section{Selin Soner Kara1 ${ }^{10}$, Gökhan Yurdakul ${ }^{2}$ ()}

${ }^{1}$ Yıldız Teknik Üniversitesi, Makine Makina Fakültesi, Endüstri Mühendisliği Bölümü, 34349, İstanbul

${ }^{2}$ Yıldız Teknik Üniversitesi, Makina Fakültesi, Endüstri Mühendisliği Bölümü, 34349, İstanbul

Sorumlu Yazar / Corresponding Author*: gokhanyurdakul25@gmail.com

Öz

21. yüzyılda gelişmiş ve gelişmekte olan ülkelerin en önemli problemlerinden birisi de trafik problemidir. Birçok ülkede trafik probleminin çözümüne yönelik planlamalar, faaliyetler ve bu soruna ilişkin harcanan zaman ve bütçeler her geçen gün artırılmaktadır. Bununla beraber literatüre bakıldığında küme örtme ve p-medyan modelleri ile yapılmış birçok çalışmaya rastlanmaktadır. Paralel olarak ulaşım üzerine yapılan çalışmalar da literatürde sıklıkla yer almaktadır. Ancak küme örtme ve alternatif servis seviyeli p-medyan modelleri ile raylı sistem üzerine yapılmış çalışmalar diğer alanlara kıyasla daha sınırlı ve az sayıdadır. Bu sebeple bu çalışmada Kocaeli ili sınırları içerisinde yer alan Gebze ve Darıca ilçelerinde yapılması planlanan metro projesi bağlamında, güzergâh üzerinde yapılacak metro hattının optimum istasyon sayısının ve istasyonların lokasyonunun belirlenmesi problemine küme kapsama ve alternatif servis seviyeli p-medyan modelleri ile çözüm aranmıştır. Sonuçlar detaylıca analiz edilmiştir.

Anahtar Kelimeler Raylı Sistem, Küme Örtme Problemi, P-Medyan Problemi, Tam Sayılı Programlama

\begin{abstract}
:
One of the most important problems of developed and developing countries in the 21st century is the traffic problem. For each country -in this context-, the plans, activities and the time and budgets allocated for the solution of the traffic problem are increasing day by day. Moreover, when the literature is examined, many studies have been made with set covering and p-median models. Parallel to these studies on transportation is frequently included in the literature. However, the studies on the rail system with set covering models are almost scarcely any. For this reason in this study, in the context of the metro project covering Gebze and Darıca districts located in Kocaeli province, the solution of the problem that the metro stations thought to be built and at which location should be
\end{abstract}


built was searched with set covering and alternative service level p-median models. The results were analyzed in detail.

Keywords Rail System, Set Covering Problem, P-Median Problem, Integer Programming

\section{Giriş}

18. yüzyıl sonrası sanayi devriminin bir getirisi olarak kentleșme ve sonrası büyük metropollerin kurulması șehir nüfuslarının geometrik artışına sebep olmuştur. Buna bağlı olarak motorlu araç talebinde de hızlı artış olmuştur. Talepteki bu artış sonrasında trafik sorununun bir bakıma ilk belirtilerini ortaya çıkmıştır.

Özellikle 19. yüzyıl sonları ve 20. yüzyılın başlarında trafik sorunu tüm gelimiş ülkelerde bașlıca sorun haline gelmiștir. Trafik sorununa ilk çözüm denemesi yeni yolların yapılması şeklinde olmuşsa da kısa dönem sonrasında bunun kesin bir çözüm olmayacağı görülmüştür. Sonrasında ise toplu taşıma düşüncesi akla gelmiştir.

Kent merkezlerinde ve çevresinde ilk toplu taşıma araçları lastik tekerlekli araçlar olmuştur ancak değişen kent yaşamı ve nüfus artış oranları raylı sistemlerin toplu taşımada kullanılmasını sağlamıştır. Bu dönemde gelișmiş ülkelerde toplu tașıma (özellikle raylı sistemlere) öncelik tanıyan ulaşım planlama çalışmaları yapılmıștır. Bu çalışmalarda da özel oto kullanımının sınırlandırılarak; eşitlikçi, çevreci, güvenli ve konforlu özellikleriyle ön plana çıkan raylı sistemlere vurgu yapılmıştır[1].

Toplu taşıma amacıyla raylı sistemlerin ilk olarak kullanılması İngiltere'de olmușsa da çok zaman geçmeden birçok ülkede raylı sistemler kullanılmaya bașlanmıștır. Yadsınamaz bir gerçektir ki toplu taşıma amacıyla raylı sistemler birçok gelişmiş ve gelişmekte olan ülkelerde trafik sonunun çözümü için ilk akla gelen uzun ömürlü, konforlu, güvenli ve ideal çözümlerden birisidir.

Günümüzde metropollerdeki nüfus artış hızına paralel olarak trafikteki araç sayısı da artmaktadır. Bununla bağlı olarak şehirlerde yaşayan insanların trafikte geçirdikleri zaman her geçen gün artmaktadır. Yanı sıra trafik sorunu her kentlinin günlük hayatında uğraşmak zorunda kaldığı sorunlardan biridir. Bu sorunun çözümü için düşük maliyetli, etkin ve verimli bir ulaşım sistemi oluşturmanın ilk şartı tüm taşıma sistemleri ile koordineli ve bütünleşmiş bir raylı sistem ağının oluşturulmasıdır [2].
Bugün günlük hayatta toplu taşıma sistemleri şehirler için daha güvenli, daha hızlı ulașım araçları olarak adlandırılmaktadır. Türkiye gibi nüfus artıș oranlarının pozitif olduğu ülkelerde kent yaşamında da taktiksel ve stratejik seviyede değişimler yaşanmaktadır. Dün için yeterli olan planlamalar yarın için yetersiz kalmaktadır. Bu sebeple toplu taşıma sistemleri için yapılan stratejik planlamalar sürdürülebilirliğin bir göstergesi durumundadır.

Günümüzde günlük hayatta toplu taşıma sistemlerinin kullanılması kentleri daha çevreci kılmakta, daha güvenli ve hızlı ulaşım olarak adlandırılmaktadır. Çubuk \& Türkmen (2003) toplu taşımacılığın özelliklede raylı sistemlerin daha eşitlikçi, daha çevreci, daha konforlu ve güvenli olduğunu ifade etmektedir [1]. Bunun yanı sıra Türkiye gibi nüfus artış oranlarının pozitif olduğu ülkelerde, kent yaşamında da taktiksel ve stratejik seviyede değişimler yaşanmaktadır. Shen vd., (2016) yaptıkları çalışma ile metro istasyonlarına yakınlığın yüksek iş olanakları sağladığını ve uzun süren gidiș gelişlerde metronun daha tercih edilebilirliğinin olduğunu gösterdi [10]. Bu açıdan metro tarzı raylı sistemlerin bir şehrin ekonomik ve sosyolojik açıdan kent sakinlerinin yaşam standartlarının artmasına pozitif katkı yapacağı söylenebilir. Bu çalıșmanın yapılma motivasyonun temelinde de bu düşünce dayalı iki sebep bulunmaktadır. Öncelikli sebep, yapılacak olan Gebze-Darıca metro projesinin optimum istasyon sayısının bulunmasını ve lokasyonlarının belirlenmesini sağlamak, bu sayede metro ulaşımını kullanacak olan kişiler için en uygun istasyon konumları belirlenmiş olacaktır. İkinci olarak da bu alandaki yazına katkı sağlamaktır.

Çalıșmada iki farklı model kullanılmıștır. Öncelikle projede optimum kaç adet metro istasyonunun olması gerektiği küme örtme modeli ile belirlenmiştir. Sonrasında alternatif servis seviyeli p-medyan modeli kullanılarak belirlenmiş bu istasyonların hangi mahallelere hizmet verdiği belirlenmiştir. Proje kapsamında proje yürütücüleri tarafından belirlenmiş çok sayıda farklı istasyon lokasyonları bulunmaktadır. $\mathrm{Bu}$ çalışmanın amaçlarından 
birisi de bu lokasyonların hangilerinin en uygun istasyon noktaları olduğunun belirlenmesidir.

Diğer yandan küme örtme modeli kullanılarak elde edilen sonuçların alternatif servis seviyeli pmedyan modeli için bir girdi olarak kullanılması farklı bir yaklașım olacağından literatüre katkı yapacağı düşünülmektedir.

$\mathrm{Bu}$ bağlamda Ulaștırma ve Altyapı Bakanlığı bünyesinde ve Kocaeli Büyükșehir Belediyesi ortaklığı ile Darıca ve Gebze 'yi kapsayan, trafik sorununun çözümüne yönelik yeraltı raylı metro projesi oluşturulmuştur. Belirtilen proje iki etaptan oluşmaktadır: birinci etap Darıca'dan başlayarak Gebze organize sanayi bölgesine kadar gidecek toplamda 13 duraklı bir metro projesidir. Projenin ikinci etabında ise belirtilen metro hattının Kuzey Marmara Otoyoluna entegrasyonu sağlanacaktır. $\mathrm{Bu}$ çalıșmada belirtilen proje kapsamında küme örtme modeli ile minimum istasyon sayısının belirlenerek minimum istasyon sayısı ile maksimum hizmet alacak örtünme amaçlanmaktadır.

Çalıșmanın bundan sonraki bölümleri șu șekilde dizayn edilmiștir: 2 . bölümde literatür taraması yer alacaktır. Takip eden 3. bölümde çalışmanın kapsamı hakkında bilgi verilecektir. Sonrasındaki 4 . bölümde ise uygulama ve analiz konuları yer almaktadır. Son bölüm olan 5 . bölüm ise sonuç ve tartışma bölümüdür.

\section{Literatür Taraması}

Literatüre bakıldığında toplu taşıma ve demiryolu üzerine sayısız çalışma görülmektedir. Genel olarak yapılan çalışmalar: toplu taşıma araçlarının seçimi (lastikli araçlar, metro, hafif raylı sisteler vs), güzergâh seçimi, raylı sistemler için optimum durak lokasyonlarının belirlenmesi üzerine yoğunlașmıştır. Bununla beraber küme örtme/kapsama, p-medyan gibi ağ optimizasyonu modelleri üzerine de geniş bir alanda çok fazla akademik çalıșma yapılmıștır. Bahsedilen konular üzerine yapılan çalıșmaların tamamına değinmek neredeyse olanaksızdır. Așağıda sadece küçük bir kısmına değinilmiştir;

Dinç vd. (2019) yaptıkları çalışmada AnkaraSivas yüksek hızlı tren hattında istasyon yerlerinin seçimi konusuna AHP ve hedef programlama modelleriyle çözüm aramışlardır. Çalıșmada, belirlenen kriterler ıșığında AHP ile ağırlıklar belirlenip bu ağırlıklar hedef programlama modeline uygulanmış ve dört șehir için optimum yerleşim lokasyonu belirlenmiştir
[3]. Kırlangıçoğlu (2016) kent içi raylı sistem koridor seçimi problemine Coğrafi Bilgi Sistemleri ve birçok kriterli karar verme yöntemi olan "Çok Katmanlı Ağırlıklı Çakıștırma Yöntemi" modelleri kullanarak çözüm aramıştır. Çalışmada İstanbul ili içerisinde mevcut talebe yönelik raylı ulaşım koridorları belirlenmeye çalışılmıştır. Yolculuk talebi, nüfus yoğunluğu gibi 12 farklı kriter üzerinden tasarım modeli analiz edilmiştir [4]. Süt vd. (2018) Analitik Hiyerarşi Prosesi kullanarak Ankara-Sivas Yüksek Hızlı Tren hat güzergahının değerlendirmesini yapmışlardır. Çalışmada 5 kriter ıșığında AHP kullanılarak güzergâh üzerindeki șehirlerin genișlemeye müsait olduğu sonucuna varmışlardır [5].

Liu vd. (2010) yaptıkları çalıșmada bulanık TOPSIS kullanarak var olan bir demiryolu hattına yeni istasyonların eklenmesi sorununu analiz etmişlerdir [6]. Smith (1993) çalışmasında bulanık doğrusal katkı ağırlığı yöntemi ile bir demiryolu ağına eklenecek 3 farklı yeni hattın her birisi için bir dizi yeni tren istasyonu yer seçim probleminin analizini yapmıștır. Çalışmada yeni bir yöntem önerisi ile en uygun istasyon lokasyonlarının nereleri olacağı incelenmiştir [7]

Yang vd. (2016) yaptıkları çalıșmada Shenzhen metro hattı için istasyon lokasyonu seçim problemini ele almışlardır [8]. Mohajeri ve Âmin (2010) yaptıkları çalışmada raylı sistem istasyon lokasyon seçimini Analitik Hiyerarşi Prosesi (AHP) ve Veri Zarflama Analizi (VZA) kullanarak yapmıșlardır. Çalıșmada AHP ile seçeneklerin ağırlıkları belirlenmiș ve bu ağırlıklar VZA modeli için bir çıktı verisi olarak kullanılmış, bu sayede 5 farklı alternatifin etkinlik seviyelerini analiz edilmiștir [9]. Shen vd. (2014) Portekiz Aveiro şehri için yüksek hızlı tren güzergahı için belirlenen 2 farklı güzergahın şehre etkisini ve hangisinin daha uygun olduğunun araştırmasını yapmaktadır. Çalışmada ajan tabanlı benzetim modeli kullanarak yüksek hızlı tren için etki analizi yapılmıştır. Analiz sonuçlarına göre yüksek hızlı tren istasyonunun şehirden uzakta olmasının şehre hiçbir faydasının olmadığını ancak şehirdeki mevcut demir yolu istasyonuna entegre edilmesi durumunda șehre katma değer kattığı gözlemlenmiștir [10]. Blainey ve Preston (2013) yaptıkları çalışmada coğrafi bilgi sistemi tabanlı bir model kullanarak yeni yerel raylı sistem istasyon yeri belirlenmesi konusunu ele almıșlardır. Çalıșmada istasyon lokasyonlarının belirlenmesinde dikkate alınması gereken 
kriterlerin neler olduğunu belirtilerek coğrafi ağırlıklı regresyon analizi ile en uygun yerin belirlenebileceği söylenmektedir [11].

Aktaş vd. (2009) çalıșmalarında İstanbul'da itfaiye istasyon yerlerinin seçimi için küme kapsama tabanlı bir model önermektedirler. Çalışmada varolan itfaiye yerlernin etkinliğine değinilmeden yeni yapılması düşünülen istasyonların nerelere yapılması gerektiği üzerinde durulmuş ve toplamda 70 yeni istasyonun açılması durumunda İstanbul halkının tamamının kapsanacağı belirtilmiştir [12]. Çatay vd. (2008) yaptıkları çalışmada küme kapsama ve maksimum küme kapsama tabanlı yedek çift kapsama modelini (YÇKM) önermişler ve İstanbul'da acil yardım istasyonlarının yerlerinin belirlenmesinin analizini yapmıșlardır. Çalıșmada tek dönemli YÇKM ve çift dönemli YÇKM modelleri için üç farklı sezgisel algoritma ile çözüm aranmıştır. Sonuç olarak miyop algoritması daha hızlı sonuc verirken DP gevşetmesi daha iyi sonuç vermiștir. Yazarların önerdiği kombinasyonlu gevşetme yöntemi ise diğer iki yöntemden daha kötü sonuç vermiştir [13].

Keçeci vd. (2017) yaptıkları çalıșmada atık elektrikli ve elektronik eşyaların toplanma noktaları için küme kapsama modeli kullanmışlardır. Çalışmada Ankara Çankaya ilçesi içerisinde atık elektrikli ve elektronik eşyaların toplanma araçlarının konumlandırılması gereken lokasyonları küme kamsama modeli ile modelleyip 21 noktada AEEE toplama kumbarası konulması gerektiği sonucuna varmıșlardır [14]. Atalay (2016) yaptığı çalışmada Türkiye genelinde ortak sağlık güvenlik biriminin şube yerlerinin küme örtme yaklașımı ile analiz etmiștir [15]. Yelbay vd. (2014) çalışmalarında küme kapsama modeli çözümü için geliştirilen sezgisel algoritmalara dual değerlendirme açısından yaklașmıșlardır. Çalışmanın sonuçlarına göre araştırmacıların yaklașımı model büyüdükçe dual yaklașım hem optimal çözüm açısından hem de zaman açısından önemli kazançlar sağlamaktadır [16].

Şahin ve Hazırcı (2019) yaptıkları çalışmada Burdur'da yașanılacak olası bir deprem felaketinde kullanılabilecek iskanların seçimi ve bu alanlara ataması yapılacak mahallelerin belirlenmesini amaçlamıșlardır. Çalıșmada öncelikle Analitik Hiyerarşi Prosesi (AHP) ile belirli kriterler üzerinden farklı iskân alanı alternatiflerin seçimi yapılmış sonrasında ise pmedyan modeli ile mahallelerin hangi alanlara atanacağı belirlenmiștir. Çalıșma sonucunda dokuz alternatiften altısının geçici iskân alanı olarak kullanılabileceği görülmüştür [30].

Yukarıda çok az bir kısmına değinilen literatür taramasından da anlaşılacağı üzere küme örtme ve p-medyan modelleri birçok araştırmacı tarafından sıklıkla kullanılan matematiksel modellerdendir ve bu konularda literatürde yeterince çalışmaya rastlamak mümkündür. $\mathrm{Bu}$ çalışmada da benzer şekilde hem küme örtme modeli hem de alternatif servis seviyeli pmedyan modeli kullanılmıștır. Her ne kadar belirtilen bu modeller literatürde sıklıkla kullanılmıș ise de küme örtme modelinin çıtılarının alternatif servis seviye p-medyan modeli için girdi olarak kullanılması yani bir bakıma iki modelin hibritlenerek kullanılması yeni bir yaklaşımdır. Bu açıdan literatüre katkı yapacağı düșünülmektedir. İkinci olarak, daha öncede belirtildiği üzere literatürde raylı sistemler üzerine birçok çalışma olmasına rağmen küme örtme ve alternatif servis seviyeli p-medyan modellerinin birlikte kullanılarak metro istasyon yer seçimi üzerine yapılmış bir çalışmaya rastlamak diğer konulardaki çalışmalara nazaran oldukça zordur. Bu sebeple çalışmanın literatüre katkı yapacağı düşünülmektedir.

\section{Calıșmanın Cerçevesi}

Bu çalıșma Türkiye Ulaștırma ve Alt Yapı Bakanlığının bünyesinde Kocaeli ili GebzeDarıca ilçelerini kapsayan bir metro projesi özelinde, minimum istasyon sayısı ile maksimum hizmet alacak bölgenin kapsanmasını sağlayacak problemi ele almaktadır. Çalıșmada iki farklı model kullanılmıștır. Öncelikle küme kapsama/örtme modeli ile güzergâh üzerinde hizmet alması düşünülen her bir ilçeyi örtecek/kapsayacak minimum istasyon sayısı belirlenecek, sonrasinda alternatif hizmet seviyeli p-medyan modeliyle farklı seviyelerde hizmet alacak bölgelerin durumu incelenecektir.

Genel olarak literatüre bakıldığında raylı sistemler veya toplu taşıma sistemleri gibi konularda literatürde birçok çalışmaya rastlamak mümkündür anca küme kapsama veya alternatif servis seviyeli p-medyan modeli ile raylı sistemler üzerine yapılmış çalışmalara diğer alanlardaki çalışamalra kıyasla daha az karşılașılmaktadır [32,33]. Bu açıdan yapılan bu çalışmanın literatüre katkı sağlayacağını düşünüyoruz. 
İlgili proje aşağıdaki Şekil 1'de de görüleceği üzere Darıca ilçesinden başlayan ve Gebze organize sanayi bölgesine kadar uzanan 13 istasyonlu, toplamda $14 \mathrm{~km}$ uzunluğunda ve yaklaşık beş milyar € bütçeli bir projedir.

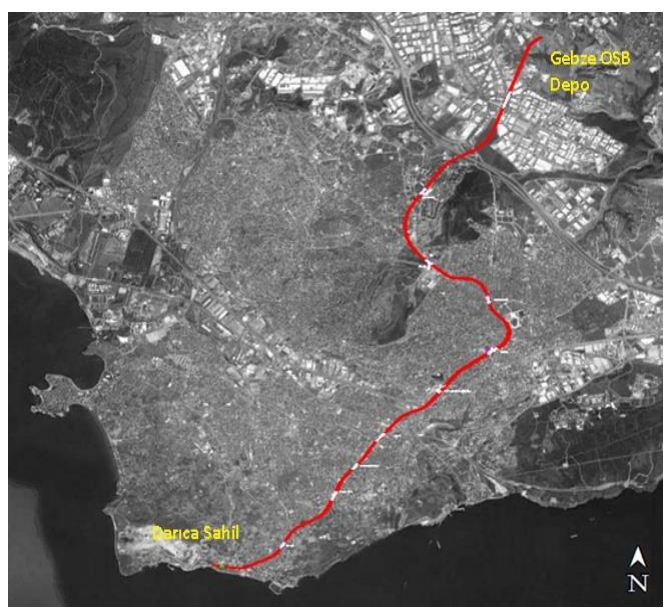

Şekil 1. Metro hattı güzergahı

\section{Uygulama ve Analiz \\ 4.1. Küme Örtme Modeli}

Küme örtme problemi temelde bir bölgedeki ilgili hizmet alacak yapıları (müşterileri) maksimum seviyede kapsayacak minimum sayıdaki hizmet noktasını (tesisler) araştıran bir tam sayllı matematiksel programlama modelidir. Genel olarak tesis yerleşim problemleri ile ağ optimizasyonu konuları içerisinde yer alır. En genel küme örtme modeli aşağıdaki gibidir $[15,17,26,28]$.

$\min z=\sum_{j=1}^{n} x_{j}$

st:

$\sum_{j}^{n} a_{i j} X_{j} \geq 1 \quad i=1, \ldots, m$

$X_{j} \in(0,1) \quad j=1, \ldots, n$

Burada n: tesisin kurulabileceği alternatif lokasyonların sayısını gösterirken $m$ ise kapsanacak lokasyon sayısını gösterir. $a_{i, j}$ ise $i$. müşterinin j. tesisten hizmet alıyorsa 1 , diğer durumlarda 0 olan parametredir veya i. nokta j'deki tesis tarafından örtülüyorsa 1 , değilse 0 değerini alır diyebiliriz. Bunu sağlamak için de maksimum hizmet alabilecek uzaklığın belirlenmesi gerekir yani örneğin maksimum hizmet alma sınırını "Dc" olarak tanımlarsak $a_{i, j}$ değişkeni aşağıdaki duruma gelecektir.

$a_{i, j}=\left\{\begin{aligned} a_{i, j} \leq \text { DC ise } a_{i, j} & =1, \\ \text { d.d. } \quad a_{i, j} & =0\end{aligned}\right\}$

\subsection{P-Medyan Modeli}

P-medyan modeli tesis yer seçimi problemleri için çok sıklıkla kullanılan ve belki de tesis yeri seçimi konusunda literatürde en fazla çalışma yapılan bir tam sayılı matematiksel modeldir. Pmedyan modeli tesis yerleșim modelleri sınıfında yer almaktadır. P-medyan modelinin ayrıltılı olarak formülize eden ilk kişi Hakimi'dir [18]. P-medyan modelinin en genel hali 1medyan tipi modeldir. $\mathrm{Bu}$ model tüm talep noktalarına hizmet verecek bir tesisin optimum noktasını belirlemeye çalışmaktadır. Problemde amaç maliyetlerin minimize edilmesidir. Eğer açılması gereken tesis sayısı birden fazlaysa model p-medyan olarak tanımlanır [19]. Modelin temel amacı ağırlıklı maliyetin minimize edilmesidir. Modelin matematiksel gösterimi aşağıdaki gibidir[31]:

$\max z=\sum_{i} \sum_{j} h_{i} d_{i j} y_{i j}$

st:

$\sum_{i} y_{i j}=1 \quad i, j=1, \ldots n$

$\sum_{j} x_{j}=P \quad i=1, \ldots n$

$y_{i j} \leq x_{j} \quad i, j=1, \ldots n$

$y_{i j} \in(0,1)$

$\forall i, j$

$x_{j} \in(0,1)$

$\forall i, j$

Burada:

$\mathrm{i}=$ Müşteriler

$\mathrm{j}=$ Aday tesis noktaları

$\mathrm{P}=$ Açılması düşünülen tesis sayısı

$\mathrm{h}_{\mathrm{i}}=\mathrm{i}$. müşterinin talebi

$\mathrm{d}_{\mathrm{ij}}=\mathrm{i}$. müşterinin j. tesise olan uzaklığ

$\mathrm{y}_{\mathrm{ij}}=\{$ i. müşteri j. tesise atanmışsa: $1, \mathrm{dd}: 0\}$

$\mathrm{x}_{\mathrm{j}}=\{\mathrm{j}$. noktada tesis açılmışsa: $1, \mathrm{~d} . \mathrm{d} .=0\}$ 


\subsection{Alternatif Servis Seviyeli P-Medyan Modeli}

Bazı durumlarda müșteriler en yakın olan tesisten değil de ikincil yakındaki bir tesisten hizmet almak isteyebilirler. Bunun birçok sebebi olabilir. Örnek vermek gerekirse kişiye en yakın tesis çok yoğun olabilir, o tesisten hizmet alma süresi çok uzun olabilir veya hizmet standarttı istenilen seviyede olmayabilir. $\mathrm{Bu}$ durumda kişiler alternatif servis vericilere yönlenebilirler [20]. Faharani vd. (2012) bu durumu șöyle açıklamaktadırlar: Birincil (en yakın) tesisin dışında kullanılabilcek en yakın tesis yedek tesis veya ikincil tesis olarak adlandırılır $[20,21]$.

Yukarıda açıklanan durum üç alternatif üzerinden belirlenmek istenirse; öncelikli hedef, ikincil öncelikli hedef ve üçüncül öncelikli hedef olarak belirlenebilir veya bunun yerine yüksek servis seviyesi (YSS), ortalama servis seviyesi (OSS) ve maksimum servis seviyesi (MSS) olarakda belirlenebilir. Burada öncelikli amaç YSS'yi maksimize etmektir. Sonrasında OSS ve en son da MSS'yi maksimize etmektir. Bu durumda ilgili p-medyan modeli aşağıdaki gibi olur [22].

$$
\max z=\sum_{i} \sum_{j}\left(a_{i j}>Y S S ? 0: 1\right) h_{i} y_{i j}
$$

st:

$\sum_{i} \sum_{j} h_{i} d_{i j} y_{i j}<\left(\right.$ OSS ? 0: 1) $\sum_{i} h i$

$y_{i j} \leq 1\left(d_{i j}>M S S\right.$ ? 0:1)

$y_{i j} \leq x_{j}$

$\sum_{j} x_{j}=$

$y_{i j} \in(0,1)$

$i=1, \ldots n$

$x_{j} \in(0,1)$

$i, j=1, \ldots n$

$\mathrm{i}=$ Müşteriler

$\mathrm{j}=$ Aday tesis noktaları

$\mathrm{P}=$ Açlması düşünülen tesis sayısı

$\mathrm{h}_{\mathrm{i}}=\mathrm{i}$. müşterinin talebi

$\mathrm{d}_{\mathrm{ij}}=\mathrm{i}$. müşterinin j. tesise olan uzaklığ

$\mathrm{y}_{\mathrm{ij}}=\{\mathrm{i}$. müşteri j. tesise atanmışsa: $1, \mathrm{dd}: 0\}$

$\mathrm{x}_{\mathrm{j}}=\{\mathrm{j}$. noktada tesis açılırsa: $1, \mathrm{~d} . \mathrm{d} .=0\}$

YSS $=$ Yüksek Servis Seviyesi

OSS $=$ Ortalama Servis Seviyesi
MSS = Maksimum Servis Seviyesi

Yukarıdaki alternatif servis seviyeli p-medyan modeli 2 no'lu modelden birçok noktada farklılık göstermektedir. Öncelikle 10 no'lu denklemde hizmet alma uzaklığı yüksek servis seviyesinden büyük olma koșulu eklenmiștir. Eğer servis alma uzaklığı belirlenen yüksek servis seviyesinden (YSS) büyükse 0 , değilse 1 olarak atanacaktır. İkinci olarak 11 no'lu denklemde ise ortalama servis seviyesini sağlaması gerekmektedir. Son olarak 12 no'lu denklem ise maksimum servis seviyesini garanti altına almaktadır.

\subsection{Uygulama}

Çalışmada Gebze ve Darıca ilçelerinde yapılması planlanan metro projesi için öncelikle küme örtme modeli ile modele dahil edilcek ilçelerin minimum istasyon sayısı ile kapsanması araştırılmıştır. Proje için belirlenen güzergâh Darıca sahilden başliyor ve Gebze OSB bölgesinde son buluyor. Proje genelinde toplamda 13 durak belirlenmiş ve bu duraklar aşağıdaki gibidir:

- Darıca sahil durağı

- Darıca Cumhuriyet Meydanı durağ

- Farabi Araştırma Hastanesi durağı

- Darıca Adnan Menderes Kültür Merkezi durağ

- TCDD Marmaray istasyon durağı

- Gebze Fatih Devlet Hastanesi durağı

- Gebze Kent Meydanı durağı

- Gebze Stadyum durağ

- $\quad$ Akse Sapağı durağı

- Gebze Adliye Sarayı durağ

- Mutlukent durağı

- Gebze Organize Sanayi Bölgesi durağı

- Gebze OSB Depo durağı

Darıca ve Gebze ilçeleri içerisinde -her bir köyü de mahalle olarak sayarsak- sırasıyla 14, 40 mahaleye sahiplerdir. $\mathrm{Bu}$ çalışmada bu mahallelerin toplamda 28 tanesi dikkate alınmıștır. Bunun sebebi çalıșmaya dahil edilmeyen mahallelerin güzergaha ve güzergâhtaki olası istasyonlara olan uzaklığıdır. Blainey ve Prest (2013)'e göre istasyonların hizmet alacak yolculara uzaklığı ortalama 1,5 $\mathrm{km}$, maksimum $2 \mathrm{~km}$ olmalıdır [11]. Bu sebeple herhangi bir durağa $2 \mathrm{~km}$ 'den fazla uzaklıkta olan mahalleler bu çalışmaya dahil edilmemiştir. Așağıda ki Tablo 1 ve Tablo 2'de Darıca ve Gebze ilçelerine ait mahalleleri ve nüfus bilgileri gösterilmektedir. 
Tablo 1. Darıca nüfus bilgileri

\begin{tabular}{|c|c|c|c|}
\hline Yll & İlçe & Mahalle Adı & $\begin{array}{l}\text { Mahalle } \\
\text { Nüfusu }\end{array}$ \\
\hline 2018 & Darıca & $\begin{array}{l}\text { K. Karabekir } \\
\text { Mah. }\end{array}$ & 39.380 \\
\hline 2018 & Darica & Osmangazi Mah. & 27.855 \\
\hline 2018 & Darica & Bağlarbaşı Mah. & 26.297 \\
\hline 2018 & Darica & $\begin{array}{l}\text { Nene hatun } \\
\text { Mah. }\end{array}$ & 22.809 \\
\hline 2018 & Darica & $\begin{array}{l}\text { Fevzi Çakmak } \\
\text { Mah. }\end{array}$ & 19.193 \\
\hline 2018 & Darica & $\begin{array}{l}\text { Sıra Söğütler } \\
\text { Mah. }\end{array}$ & 13.669 \\
\hline 2018 & Darica & $\begin{array}{l}\text { Abdi İpekçi } \\
\text { Mah. }\end{array}$ & 12.706 \\
\hline 2018 & Darıca & Cami Mah. & 8.213 \\
\hline 2018 & Darica & Yeni Mah. & 1.756 \\
\hline 2018 & Darica & $\begin{array}{l}\text { Zincirlikuyu } \\
\text { Mah. }\end{array}$ & 1.496 \\
\hline 2018 & Darica & Yalı Mah. & 1.162 \\
\hline
\end{tabular}

\begin{tabular}{llll}
\hline 2018 & Gebze & M. Paşa Mah. & 18.653 \\
\hline 2018 & Gebze & Mevlâna Mah. & 17.139 \\
\hline 2018 & Gebze & Yeni kent Mah. & 16.933 \\
\hline 2018 & Gebze & Tatlı kuyu Mah. & 15.961 \\
\hline 2018 & Gebze & Ulus Mah. & 13.788 \\
\hline 2018 & Gebze & Sultan Orhan Mah. & 12.032 \\
\hline 2018 & Gebze & Hürriyet Mah. & 11.844 \\
\hline 2018 & Gebze & İnönü Mah. & 11.438 \\
\hline 2018 & Gebze & Yavuz Selim Mah. & 11.332 \\
\hline 2018 & Gebze & Hacı Halil Mah. & 9.725 \\
\hline 2018 & Gebze & Balçık Mah. & 1.359 \\
\hline 2018 & Gebze & Eski Hisar Mah. & 539 \\
\hline
\end{tabular}

Küme örtme modellerinde temel amaç belirli bir mesafede ki müșterileri kapsayacak minimum tesis sayısını bulmaktır. Bu açıdan literatüre bakıldığında raylı sistem toplu tașıma projelerindeki hedef kitleler ilgili durağa maksimum 10dk (azami $2 \mathrm{~km}$ ) uzaklıkta ki kişilerdir. Bu sebeple herhangi bir durağa çok uzakta olan kișilerin kapsanması anlamsızdır $[15,23]$. Așağıda ki Tablo 3 ve Tablo 4'de Darıca ve Gebze ilçelerine ait herbir mahallenin güzergahta belirlenmiș duraklara olan uzaklıkları gösterilmektedir.

Tablo 2. Gebze nüfus bilgileri

\begin{tabular}{cccc}
\hline Yıl & İlçe & Mahalle Adı & $\begin{array}{c}\text { Mahalle } \\
\text { Nüfusu }\end{array}$ \\
\hline 2018 & Gebze & A. Çeşme Mah. & 32.589 \\
\hline 2018 & Gebze & O. Yılmaz Mah. & 31.865 \\
\hline 2018 & Gebze & K. Çeşme Mah. & 24.287 \\
\hline 2018 & Gebze & Gaziler Mah. & 21.408 \\
\hline 2018 & Gebze & Güzeller Mah. & 20.203
\end{tabular}

Tablo 3. Darıca mahalleri ve istasyonlara olan uzaklıklar $(\mathrm{km})$

\begin{tabular}{|c|c|c|c|c|c|c|c|c|c|c|c|c|}
\hline \multicolumn{2}{|c|}{ Mahalle } & $\begin{array}{l}\text { K.K. } \\
\text { Bekir }\end{array}$ & $\begin{array}{l}\text { O. } \\
\text { Gazi }\end{array}$ & $\begin{array}{l}\text { B. } \\
\text { Bașı }\end{array}$ & $\begin{array}{l}\text { N. } \\
\text { Hatun }\end{array}$ & $\begin{array}{l}\text { F. } \\
\text { Çakmak }\end{array}$ & $\begin{array}{l}\text { S. } \\
\text { Söğütler }\end{array}$ & $\begin{array}{l}\text { A. } \\
\text { İpekçi }\end{array}$ & Cami & Yeni & $\begin{array}{l}\text { Z. } \\
\text { Kuyu }\end{array}$ & Yalı \\
\hline \multirow{13}{*}{ 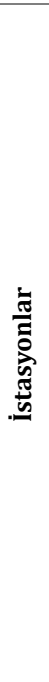 } & $\dot{\mathbf{I}}_{1}$ & 3,2 & 3,9 & 1 & 3,1 & 3 & 4 & 3,5 & 2,2 & 0,75 & 0,8 & 0 \\
\hline & $\dot{\mathbf{I}}_{2}$ & 2,67 & 3,1 & 0,5 & 2,4 & 2,6 & 3,3 & 3,2 & 0 & 0,5 & 0,5 & 0,5 \\
\hline & $\dot{\mathbf{I}}_{3}$ & 1,15 & 3,2 & 1,6 & 2 & 0 & 2,35 & 1,25 & 3,2 & 2,45 & 2,5 & 2,5 \\
\hline & $\dot{\mathbf{I}}_{4}$ & 0 & 2,95 & 2,2 & 1,8 & 0,5 & 1,75 & 1 & 3,6 & 3 & 2,9 & 3 \\
\hline & $\dot{\mathbf{I}}_{5}$ & 1 & 3,5 & 3,1 & 2,45 & 1 & 0 & 0,5 & 4,5 & 4 & 3,75 & 3,75 \\
\hline & $\dot{\mathbf{I}}_{6}$ & 2,05 & 4,2 & 4,2 & 3,4 & 2,15 & 2,6 & 1,6 & 5,5 & 5,1 & 5 & 5 \\
\hline & $\dot{\mathbf{I}}_{7}$ & 3,18 & 5,2 & 5,3 & 15 & 15 & 15 & 15 & 15 & 15 & 15 & 15 \\
\hline & $\dot{\mathbf{I}}_{8}$ & 3,87 & 5,75 & 6 & 15 & 15 & 15 & 15 & 15 & 15 & 15 & 15 \\
\hline & $\dot{\mathbf{I}}_{9}$ & 3,9 & 5,5 & 6,15 & 15 & 15 & 15 & 15 & 15 & 15 & 15 & 15 \\
\hline & $\dot{\mathbf{I}}_{10}$ & 3,42 & 4,65 & 5,75 & 15 & 15 & 15 & 15 & 15 & 15 & 15 & 15 \\
\hline & $\dot{I}_{11}$ & 5,63 & 6,3 & 8,1 & 15 & 15 & 15 & 15 & 15 & 15 & 15 & 15 \\
\hline & $\dot{I}_{12}$ & 8,45 & 8,8 & 10,6 & 15 & 15 & 15 & 15 & 15 & 15 & 15 & 15 \\
\hline & $\dot{I}_{13}$ & 10,6 & 10,9 & 12,5 & 15 & 15 & 15 & 15 & 15 & 15 & 15 & 15 \\
\hline
\end{tabular}


Tablo 4. Gebze mahalleri ve istasyonlara olan uzaklıklar (km)

\begin{tabular}{|c|c|c|c|c|c|c|c|c|c|}
\hline & & A. & & K. & Gaziler & Güzeller & M. Pașa & Mevlâna & Yenikent \\
\hline & $\dot{\mathbf{I}}_{1}$ & 15 & 15 & 15 & 15 & 15 & 15 & 15 & 15 \\
\hline & $\dot{\mathbf{I}}_{2}$ & 15 & 15 & 15 & 15 & 15 & 15 & 15 & 15 \\
\hline & $\dot{\mathbf{I}}_{3}$ & 15 & 15 & 15 & 15 & 15 & 15 & 15 & 15 \\
\hline & $\dot{\mathbf{I}}_{4}$ & 15 & 15 & 15 & 15 & 15 & 15 & 15 & 15 \\
\hline & $\dot{\mathbf{I}}_{5}$ & 4,15 & 1 & 1,75 & 4,5 & 3,1 & 2,3 & 2,6 & 5 \\
\hline & $\dot{\mathbf{I}}_{6}$ & 2,75 & 0 & 1,5 & 3,35 & 2,25 & 1,4 & 1,6 & 4 \\
\hline อี & $\dot{\mathbf{I}}_{7}$ & 1,6 & 1,5 & 2,25 & 2,75 & 1,15 & 1,65 & 1,25 & 3,5 \\
\hline. & $\dot{\mathbf{I}}_{8}$ & 0,9 & 2 & 2,75 & 2,5 & 0,75 & 0,85 & 1,5 & 3,25 \\
\hline & $\dot{\mathbf{I}}_{9}$ & 1,15 & 2,25 & 2,5 & 1,75 & 0,45 & 0,9 & 1 & 3,5 \\
\hline & $\dot{\mathbf{I}}_{10}$ & 2,25 & 2,25 & 1,9 & 1,7 & 1,5 & 2,25 & 0,75 & 2,25 \\
\hline & $\dot{\mathbf{I}}_{11}$ & 3,5 & 4,5 & 4,15 & 1,3 & 3 & 3,45 & 3 & 0 \\
\hline & $\dot{\mathbf{I}}_{12}$ & 5 & 7 & 6,75 & 3,5 & 5 & 5,75 & 5,25 & 3 \\
\hline & $\dot{I}_{13}$ & 6,75 & 8,75 & 8,75 & 5,5 & 6,75 & 7,5 & 7,15 & 5 \\
\hline
\end{tabular}

Tablo 4.1. Gebze mahalleri ve istasyonlara olan uzaklıklar (km)

\begin{tabular}{|c|c|c|c|c|c|c|c|c|c|c|}
\hline \multicolumn{2}{|c|}{ Mahaller } & Tatlıkuyu & Ulus & S. & Hürriyet & İnönü & Y. Selim & Hacıhalil & Eskihisar & Balçık \\
\hline \multirow{13}{*}{ 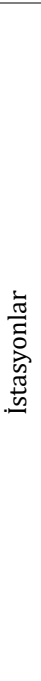 } & $\dot{\mathbf{I}}_{1}$ & 15 & 15 & 15 & 15 & 15 & 15 & 15 & 3,75 & 15 \\
\hline & $\dot{\mathbf{I}}_{2}$ & 15 & 15 & 15 & 15 & 15 & 15 & 15 & 3,75 & 15 \\
\hline & $\mathbf{I}_{3}$ & 15 & 15 & 15 & 15 & 15 & 15 & 15 & 2 & 15 \\
\hline & $\dot{\mathbf{I}}_{4}$ & 15 & 15 & 15 & 15 & 15 & 15 & 15 & 2,15 & 15 \\
\hline & $\dot{\mathbf{I}}_{\mathbf{5}}$ & 2 & 2,25 & 4,3 & 2,25 & 4,6 & 3,5 & 2,2 & 1,9 & 15 \\
\hline & $\dot{I}_{6}$ & 1 & 2 & 3,25 & 1,75 & 3,5 & 2,5 & 1 & 2,45 & 9 \\
\hline & $\mathbf{I}_{7}$ & 0,75 & 3,5 & 2,15 & 2,15 & 3,45 & 2,15 & 0 & 3,1 & 8 \\
\hline & $\dot{\mathbf{I}}_{8}$ & 1,25 & 4 & 1,75 & 2,5 & 2 & 2,15 & 1 & 3,6 & 7,5 \\
\hline & $\dot{\mathbf{I}}_{9}$ & 1,9 & 3,25 & 2,25 & 2 & 1,5 & 1,3 & 1,4 & 4,2 & 7 \\
\hline & $\dot{I}_{10}$ & 3,4 & 2,25 & 3,25 & 1,15 & 2,2 & 0,5 & 2 & 4,45 & 7 \\
\hline & $\dot{I}_{11}$ & 4,6 & 3,5 & 4,5 & 3,25 & 2,5 & 2,15 & 4,15 & 6,8 & 5 \\
\hline & $\mathbf{I}_{12}$ & 6,75 & 6 & 5,75 & 5,75 & 3,75 & 4,5 & 6,3 & 9 & 2,5 \\
\hline & $\dot{\mathbf{I}}_{13}$ & 8,5 & 8,15 & 7,15 & 7,75 & 5,5 & 6,75 & 8 & 10,9 & 0 \\
\hline
\end{tabular}

Yukarıdaki Tablo 3, Tablo 4 ve Tablo 4.1 'de Darıca ve Gebze ilçelerine ait mahallelerin metro hattına ait istasyonlara olan uzaklıkları gösterilmiştir. Uzaklıklar kilometre cinsindendir. Eğer bir mahalle herhangi bir durağa $15 \mathrm{~km}$ ve daha fazla uzaklıkta ise $15 \mathrm{~km}$ olarak alınmıștır. Bununla beraber bir mahalle eğer herhangi bir istasyona çok uzaksa (örn. 4 $\mathrm{km}$ ve üzeri) kapsam dıșı sayılmıştır. Bu bilgiler 
ışığında küme örtme modeli çözüldüğünde aşağıdaki sonuçlar elde edilmiştir.

Tablo 5. Küme örtme modeli sonuçları (hizmet alma uzaklı̆̆ $2 \mathrm{~km}$ )

\begin{tabular}{ll}
\hline \multicolumn{1}{c}{$\mathbf{x}_{\mathbf{j}}$} & Değer \\
\hline Darıca Sahil & 1,00 \\
\hline Darıca Cumhuriyet Meydanı & 0 \\
\hline Farabi Araştırma Hastanesi & 1,00 \\
\hline Darıca A. Menderes K. Merkezi & 1,00 \\
\hline TCDD İstasyon & 0 \\
\hline Gebze Fatih Devlet Hastahanesi & 0 \\
\hline Gebze Kent Meydanı & 0 \\
\hline Gebze Stadyum & 1,00 \\
\hline Akse Sapağı & 0 \\
\hline Gebze Adliye Sarayı & 1,00 \\
\hline Mutlukent & 1,00 \\
\hline Organize Sanayi Bölgesi & 0 \\
\hline OSB Depo Bölgesi & 1,00 \\
\hline
\end{tabular}

Tablo 5'te küme örtme modelinin sonuçları gösterilmektedir. $\mathrm{Bu}$ sonuçlara göre bu güzergaha minimum $2 \mathrm{~km}$ uzaklıktaki tüm alanlar yedi istasyon ile kapsanabilmektedir. Model sonuçlarına bakıldığında Darıca Sahil, Farabi Araștırma Hastanesi, Darıca Adnan Menderes Kültür Merkezi, Gebze Stadyum, Gebze Adliye Sarayl, Mutlukent ve OSB Depo Bölgesinde istasyon açılmış olması gerekli ve yeterlidir.

Daha önce de belirtildiği üzere proje kapsamında belirlenen istasyon sayısı 13 adettir; ancak yedi durak ile de bu örtünme sağlanabilmektedir. Bunun anlamı bu güzergâh üzerinde açlması gereken minimum sayıdaki istasyon yedi olmalıdır.

Bu sonuca ulașırken toplam hedef mahalle sayısı 28 olarak belirlenmiş ve hizmet alma uzaklığı 2 km olarak öngörülmüştür. Eğer hizmet alma maksimum uzaklığını 1,5 km olarak belirlersek en az bir durağa olan uzaklığı 1,5 km uzaklıktan fazla olan mahalleler modelden çkartılacaktır ve bu sefer toplam hedef mahalle sayımız 24'e düşecek. Bu durumda model sonucu aşağıda verilen Tablo 6'daki gibi olacaktır.

Tablo 6. Küme örtme modeli sonuçları (hizmet alma uzaklığ $1,5 \mathrm{~km}$ )

\begin{tabular}{ll}
\hline \multicolumn{1}{c}{$\mathbf{x}_{\mathbf{j}}$} & Değer \\
\hline Darıca Sahil & 0 \\
\hline Darıca Cumhuriyet Meydanı & 1,00 \\
\hline Farabi Araștırma Hastanesi & 0 \\
\hline Darıca A. Menderes K. Merkezi & 0 \\
\hline TCDD İstasyon & 1,00 \\
\hline Gebze Fatih Devlet Hastahanesi & 1,00 \\
\hline Gebze Kent Meydanı & 1,00 \\
\hline Gebze Stadyum & 0 \\
\hline Akse Sapağı & 1,00 \\
\hline
\end{tabular}

\begin{tabular}{ll}
\hline Gebze Adliye Sarayı & 1,00 \\
\hline Mutlukent & 1,00 \\
\hline Organize Sanayi Bölgesi & 0 \\
\hline OSB Depo Bölgesi & 1,00 \\
\hline
\end{tabular}

Tablo 6'daki sonuçlara baktığımızda toplam açılması gereken istasyon sayısı sekiz olmuştur. Bununla beraber bir önce modelde istasyon açılması gereken lokasyonlarda da değisşiklikler olmuştur.

\subsubsection{Alternatif Servis Seviyelerine Göre Problemin Analizi}

Alternatif servis seviyeli modellerde birden fazla servis seviyesi olabilir. Ama genel olarak servis seviyeleri birincil, ikincil vs. olarakda belirlenebilir veya yüksek servis seviyesi (YSS), ortalama servis seviyesi (OSS) ve maksimum servis seviyesi (MSS) olarakda adlandırılabilir. Bizim vakamıza baktığımızda j. tesiste beklenenin çok üstünde bir yoğunluk olması durumunda yolcular bir önceki veya bir sonraki duraktan servis almak isteyebilir. Böyle bir durumda yukarıda kullandığımız model bu isteğe cevap veremez. Bu duruma optimal çözüm bulmak için alternatif servis seviyeli p-medyan modeli kullanabiliriz.

$\mathrm{Bu}$ vakada ilk önceliğimiz yüksek servis seviyesinde hizmet verebilecek kapsamı belirlemek olacaktır. İkincil olarak ortalama servis seviyesi ve son olarakda maksimum servis seviyesinde hizmet verebilecek toplam örtünmeyi belirlemektir. Bunu belirlerken iki farklı seviye belirleyeceğiz ve bu seviyeler Tablo 7'de gösterildiği gibi iki farklı durum ve üç farklı servis seviyesi için yapılmıştır.

Tablo 7. Alternatif servis seviyeleri

\begin{tabular}{lll}
\hline $\begin{array}{l}\text { Servis } \\
\text { Seviyesi }\end{array}$ & 1.Durum & 2.Durum \\
\hline YSS & 1,5 & 2 \\
\hline OSS & 2,5 & 3 \\
\hline MSS & 3,5 & 4 \\
\hline
\end{tabular}

Yukarıda Tablo 7'de verilen bilgiler ışı̆̆ında alternatif servis seviyeli p-medyan modeli çözüldüğünde aşağıda gösterilen Tablo 8‘deki sonuçlara ulaşılır.

Tablo 8. Alternatif servis seviyeli p-medyan modeli

\begin{tabular}{lll}
\hline \multicolumn{1}{c}{$\mathbf{x}_{\mathbf{j}}$} & $\begin{array}{l}\mathrm{Dc}=1,5 \\
\mathrm{~km}\end{array}$ & $\begin{array}{l}\mathrm{Dc}=2 \\
\mathrm{~km}\end{array}$ \\
\hline Darıca Sahil & 1,00 & 0 \\
\hline Darıca Cumhuriyet Meydanı & 0 & 0 \\
\hline Farabi Araștırma Hastanesi & 0 & 0 \\
\hline Darıca A. Menderes K. Merkezi & 1,00 & 0 \\
\hline TCDD İstasyon & 1,00 & 1,00 \\
\hline
\end{tabular}




\begin{tabular}{lll}
\hline Gebze Fatih Devlet Hastahanesi & 1,00 & 1,00 \\
\hline Gebze Kent Meydanı & 0 & 0 \\
\hline Gebze Stadyum & 1,00 & 0 \\
\hline Akse Sapağı & 1,00 & 1,00 \\
\hline Gebze Adliye Sarayı & 0 & 1,00 \\
\hline Mutlukent & 1,00 & 1,00 \\
\hline Organize Sanayi Bölgesi & 0 & 1,00 \\
\hline OSB Depo Bölgesi & 1,00 & 1,00 \\
\hline Amaç Fonksiyonu Değeri (z) & 235132 & 300869 \\
\hline
\end{tabular}

Yukarıda Tablo 8'de alternatif servis seviyeli pmedyan modelinin sonuçları gösterilmektedir. $\mathrm{Bu}$ sonuçlara bakıldığında Dc=1,5 km için 235132 kişi bu güzergahtan hizmet alabilmektedir. Dc=2 km için ise 300869 kişi hizmet alabilmektedir. Açılması gereken istasyon lokasyonlarında da değişim gözlenmiştir. Örnek olarak Dc=2 km için küme örtme modelinde Darıca sahil, Darıca Farabi Araştırma Hastahanesi, Darıca Adnan Menderes Kültür Merkezi, Stadyum, Gebze Adliye Sarayı, Mutlukent ve OSB Depo lokasyonlarında istasyon açılması optimumken alternatif servis seviyeli modelde ise TCDD, Gebze Fatih Devlet Hastahanesi, Akse sapağı, Gebze Adliye Sarayı, Mutlukent, Organize, OSB Depo bölgelerinde açılması gereklidir. Aynı durum Dc=1,5 km için de geçerlidir.

Tablo 9. Küme Örtme ve Alternatif Servis Seviyeli P-Medyan Modelleri Sonuçları

\begin{tabular}{|c|c|c|c|c|}
\hline \multirow{2}{*}{ Alternatif İstasyon Lokasyonları } & \multicolumn{2}{|c|}{ Küme Örtme Modeli Sonuçları } & \multicolumn{2}{|c|}{$\begin{array}{c}\text { Alternatif Servis Seviyeli P- } \\
\text { Medyan Modeli Sonuçları }\end{array}$} \\
\hline & $\begin{array}{l}\text { Hizmet Alma } \\
\text { Uzaklığı 1,5 km }\end{array}$ & $\begin{array}{l}\text { Hizmet Alma } \\
\text { Uzaklığı } 2 \mathrm{~km}\end{array}$ & $\begin{array}{c}\text { Hizmet Alma } \\
\text { Uzaklığı } 1,5 \mathrm{~km}\end{array}$ & $\begin{array}{l}\text { Hizmet Alma } \\
\text { Uzaklığı } 2 \mathrm{~km}\end{array}$ \\
\hline Darıca Sahil & 0 & 1,00 & 1,00 & 0 \\
\hline Darıca Cumhuriyet Meydanı & 1,00 & 0 & 0 & 0 \\
\hline Farabi Araştırma Hastanesi & 0 & 1,00 & 0 & 0 \\
\hline Darıca A. Menderes K. Merkezi & 0 & 1,00 & 1,00 & 0 \\
\hline TCDD İstasyon & 1,00 & 0 & 1,00 & 1,00 \\
\hline Gebze Fatih Devlet Hastahanesi & 1,00 & 0 & 1,00 & 1,00 \\
\hline Gebze Kent Meydanı & 1,00 & 0 & 0 & 0 \\
\hline Gebze Stadyum & 0 & 1,00 & 1,00 & 0 \\
\hline Akse Sapağı & 1,00 & 0 & 1,00 & 1,00 \\
\hline Gebze Adliye Sarayı & 1,00 & 1,00 & 0 & 1,00 \\
\hline Mutlukent & 1,00 & 1,00 & 1,00 & 1,00 \\
\hline Organize Sanayi Bölgesi & 0 & 0 & 0 & 1,00 \\
\hline OSB Depo Bölgesi & 1,00 & 1,00 & 1,00 & 1,00 \\
\hline
\end{tabular}

Tablo 9'da iki farklı modelin iki farklı hizmet alanı için sonuçları gösterilmiştir. Hizmet alanı 1,5 km olan küme örtme modeli optimum istasyon sayısını sekiz istasyon olarak belirlemiştir. Hizmet alma mesafesi iki km olan model ise yedi istasyon sonucunu vermiștir. Bununla beraber üç istasyon her iki modelde de ortak çlkmışken diğer istasyonlar birbirinden farklı çıkmıştır.

Alternatif servis seviyeli p-medyan modeli için de aynı durum görülmektedir. Hizmet alanı 1,5 km olan küme örtme modelinde Darıca Cumhuriyet Meydanı, Darıca A. Menderes K. Merkezi Gebze Kent Meydanı, Gebze Adliyesi seçilen alternatiflerden iken alternatif servis sevile model de ise bu istasyonlar model tarafından seçilmemiştir. Aynı şekilde Darıca sahil, Farabi Araştırma Hastanesi, Darıca A. Menderes K. Merkezi, Gebze Stadyum istasyon alternatifleri, hizmet alanı iki km olan küme örtme modelinde seçilen alternatifler olurken alternatif servis seviyeli p-medyan modelinde bu alternatifler seçilmemiştir.

\section{Sonuç ve Analizler}

Yapımı kamu tarafından üstlenilen projelerin uzun vadeli, ileriye dönük, fayda öncelikli, toplumun yaşam kalitesini artıran projeler 
olması beklenmektedir. Bu sebeple yapılacak projeler detaylı, uzun ve geniș çaplı araştırmaları gerektirmektedir. Özellikle ulaşım projeleri fayda maliyet ekseninde düşünülmeli ve toplumun yaşam standartını artıran projeler olmalıdır. Bu çalışmada Darıca-Gebze ilçelerini kapsayan metro projesi baz alınarak ilgili proje güzergahında optimum istasyon sayısı ve lokasyonu, literatürde sıklıkla kullanılan küme kapsama ve alternatif servis seviyeli p-medyan modeli gibi iki farklı model üzerinden araștırılmıștır. Sonuçlar ayrıntılı olarak incelenmiştir.

Diğer yandan ise bu çalışmanın hedef ve kapsamı optimum sayıda hizmet verecek istasyon sayısını ve lokasyonunu belirlemek olduğundan maliyetlere genel olarak değinilmemiștir. Ancak çalışmanın bundan sonrası için maliyetlerinde kapsam içine alındı̆̆ı ve yukarıda belirtilen hedeflerin yanı sira bu hedeflere minimum maliyetle ulaşılacak çalışmalar yapılabilir.

İkinci olarak bu çalışmada Gebze-Darıca ilçelerini kapsayan metro projesinin ilk etabı üzerinde analizler yapılmıștır. Sonraki çalışmada ilgili projenin ikinci etabı yani bu metro hattının Kuzey-Marmara otoyolu ile birleștirilmesi de kapsama alınıp daha bütünleşik bir çalışma yapılabilir.

\section{Kaynakça}

[1] Çubuk, K., \& Türkmen, M. 2003. Ankara'da Rayl Ulaşım. Gazi Üniv. Müh. Müm. Fak. Der. 18(1):125-144

[2] Uzun, M. 2011. Erzurum Hafif Raylı Sistem Projesi Erzurum: Erzurum Düșünce ve Strateji Derneği.

[3] Dinç, S., Hamurcu, M., \& Eren, T. 2019. Ankara-Sivas Yüksek Hızlı Tren Hattında İstasyon Yerlerinin Seçiminde Çok Kriterli Karar Verme Destekli 0-1 Hedef Programlama Modeli. Demiryolu Mühendisliği, 9:1-16.

[4] Kırlangıçoğlu, C. 2016. Çok Kriterli Karar Verme Yöntemleri İle Kent İçi Raylı Sistem Koridor Planlaması. İstanbul Üniversitesi Edebiyat Fakültesi Coğrafya Dergisi, 33: 53-71.

[5] Süt, N. İ., Hamurcu, M., \& Eren, T. 2018. Analitik Hiyerarși Süreci Kullanılarak Ankara--Sivas Yüksek Hızlı Tren Hat Güzergahının Değerlendirilmesi. Harran Üniversitesi Mühendislik Dergisi, 3(3): 22-30.

[6] Leiu, T., Zou, Y., \& Xie, R. 2010. A Comprehensive Evaluation Method of Adding Passenger Station In Existing Intercity Railway Line. The Sixth Advanced Forum on Transportation of China, (s. 40-44).

[7] Smith, P. N. 1993. Fuzzy Evaluation Of Potential Suburban Railway Station Location. Journal of Advanced Transportation, 27(2):153-179.

[8] Yang, J., Chen, J., LE, X., \& Zhang, Q. 2016. Densityoriented versus development-oriented transit investment Decoding metro station location selection in Shenzhen. Transport Policy, 51: 93-102.

[9] Mohajeri, N., \& Amin, G. R. 2010. Railway station site selection using analytical hierarchy process and data envelopment analysis. Computers \& Industrial Engineering, 59(1): 107-114.

[10]Shen, Y., Silve, J. d., \& Martinez, L. 2014. HSR Station Location Choice and its Local Land Use Impacts on Small Cities: A Case Study of Averio, Potugal. Social and Behavioral Science, 111:470-479.

[11]Blainey, S. P., \& Preston, J. M. 2013. A GIS-based appraisal frame work for new local rail way stations and services. Transport Policy, 25: 41-41

[12]Aktaş, E., Özaydın, Ö., Ülengin, F., Önsel, Ş., \& Ağaran, B. 2011. İstanbul'da İtfaiye İstasyonu Yerlerinin Seçimi İçin Yeni Bir Model. Endüstri Mühendisliği Dergisi, 2-12

[13] Çatay, B., Başarı, A., \& Ünlüyurt, T. 2008. İstanbul'da Acil Yardım İstasyonlarının Yerlerinin Planlanması. Endüstri Mühendisliği Dergisi, 19(4): 20-35.

[14] Keçeci, B., Dengiz, O., Dengiz, B., Sümer, E., Kılıç, A., Çeki, E., Çiçek, S. 2017. AEEE tahmini ve toplama noktalarının belirlenmesi: Cankaya Belediyesi için bir uygulama. Pamukkale Üniversitesi Mühendislik Bilimleri Dergisi, 24(4): 692-704.

[15]Atalay, Ç. 2016. Türkiye Ölçeğinde Hizmet Vermeyi Planlayan Ortak Sağlık Güvenlik Biriminin Sube Yerşlerinin Küme Örtme Yaklaşımı İle Belirlenmesi. Social Sciences (E-Journal of New World Sciences Academy), 11(2):173-193.

[16]Yelbay, B., Birbil, İ. S., \& Bülbül, K. 2014. The Set Covering Problem Revisited: An Empirical Study of the Value of Dual Information. Journal of Operation Research, 1-22.

[17]Bakır, M. A., \& Altunkaynak, B. 2003. Tamsayılı Programlama. Ankara: Nobel Kitabevi.

[18]Hakimi, S. L. 1964. Optimum Location of Switching Centers and the Absolute Centers and Medians of a Graph. Operations Research, 12(3): 450-459.

[19]Bastı, M. 2012. P-medyan Tesis Yeri Seçim Problemi ve Çözüm Yaklaşımları. Academic Journal of Information Technology, 3(7): 47-75.

[20] Karataș, M., \& Yakıcı, E. 2019. An analysis of p -median location problem: Effects of backup service level and demand assignment policy. European Journal of Operational Research, 272(1): 207-218.

[21] Faharini, R. Z., Nasrin, A., Heidari, N., \& Hosseininia, M. 2012. Covering problems in facility location: A review. Computers \& Industrial Engineering, 62(1): 368-407.

[22]Watson, M., Lewis, S., Cacioppi, P., \& Jayaraman, J. 2012. Chapter 4: Alternative Service Levels and Sensitivity Analysis. M. WATSON, S. LEWIS, P. CACIOPPI, \& J. JAYARAMAN içinde, Supply Chain Network Desing Aplying Optimization and Analytics to the Global Supply Cahin (s. 63-79). New Jersey: FT Press. 
[23]Ballı, H. 2014. Bulanık Doğrusal Programlama Model İle Bir Kamu Kurumu İçin Tesis Yeri Seçimi. Ankara: KHO Savunma Bilimleri Enstitüsü.

[24]Evren, G. 1978. Kentsel Ulaşımda Raylı Sistemler. I Toplu Taşıma Kongresi. Ankara: Ankara Büyük Şehir Belediyesi Genel Müdürlüğü.

[25]Ocak, İ., \& Manisalı, E. 2006. Kentsel Raylı Taşıma Üzerine Bir İnceleme (İstanbul Örneği). SAÜ Fen Bilimleri Enstitüsü Dergisi , 10(2): 51-59.

[26] Kara, A. 2014. Ağ Ömrünü En Büyükleme Amaçlı Küme Kapsama Problemleri. Kayseri: Erciyes Üniversites Fen Bilimleri Enstitüsü.

[27]Yankaya, U., \& Celik, M. 2016. Kamu Ulașım Yatırımlarının Gayrimenkul Değerleri Üzerine Etkisinin Modellenmesi: İzmir Metrosu Örneği . İnşaat Mühendisleri Odası: http://www.imo.org.tr/resimler/ekutuphane/pdf/3 109.pdf adresinden alındı

[28]Yelbay, B. 2009. Primal-Dual Heuristic For Solving The Set Covering Problem. İstanbul: Sabancı Üniversitesi Mühendislik ve Fen Bilimleri Enstitüsü.
[29] Dinç, S., Hamurcu, M., \& Eren, T. 2019. Ankara-Sivas Yüksek Hızlı Tren Hattında İstasyon Yerlerinin Seçiminde Çok Kriterli Karar Verme Destekli 0-1 Hedef Programlama Modeli. Demiryolu Mühendisliği, 9:1-16.

[30]ŞAHIN, Yusuf, and Murat HAZIRCI. "Geçici İskân Alanlarının Seçimi için AHP Temelli P-Medyan Modeli: Burdur Örneği." Mühendislik Bilimleri ve Tasarım Dergisi 7.2 (2019): 403-417.

[31]Upchurch, C., \& Kuby, M., 2010. Comparing the pmedian and flow-refueling models for locating alternative-fuel stations. Journal of Transport Geography 18(6): 750-758.

[32]Zhao, L., Li, H., Li, M., Sun, Y., Hu, Q., Mao, S., ... \& Xue, J. (2018). Location selection of intra-city distribution hubs in the metro-integrated logistics system. Tunnelling and Underground Space Technology, 80, 246-256.

[33] Farahani, R. Z., Miandoabchi, E., Szeto, W. Y., \& Rashidi, H. (2013). A review of urban transportation network design problems. European Journal of Operational Research, 229(2), 281-302. 